\title{
Semiotic processes implied in the High Dilution phenomena
}

\author{
Gheorghe Jurj \\ Universitatea de Vest Timisoara, Romania
}

\begin{abstract}
Semiotic processes ( or semiosis) refer to those process which are carriers of meaning and are performed through signs. A sign is something that stands for something else, and is the main mediating factor between an object and an interpreter, able to connect them and give rise to significations. The semiotic perspective, according to Charles Sanders Peirce, is basically triadic: all aspects of reality are triadic, comprising the categories of Firstness, Secondness, and Thirdness in a continue and virtually infinite process of semiosis, i.e of various forms of giving rise to meanings that accordingly will generate reactions, actions and transformations. The aim of the present paper is to examine the possible levels of semiosis implied in the high dilution phenomenon, beginning with the process of so called "potency" of substrata (where every potency may be considered a sign for the next one) and arriving to the complex responses of the living bodies to infinitesimal signs.
\end{abstract}

\section{(c)) BY-NC-ND Licensed to GIRI}

Support: authors declare that this study received no funding Conflict of interest: authors declare there is no conflict of interest

Correspondence author: Gheorghe Jurj, relujurj@gmail.com

How to cite this article: Jurj G. Semiotic processes implied in the High Dilution phenomena. Int J High Dilution Res [online]. 2011 [cited YYYY Month dd]; 10(35): 68-68. Proceedings of the XXIV GIRI Symposium; 2010 Nov 05; Monte Carlo (Monaco). GIRI; 2010. Available from: http://www.feg.unesp.br/ ojs/index.php/ijhdr/article/view/447/463 